\title{
Aproximação à historiografia da arquitetura colonial brasileira as ideias de John Bury
}

\author{
An approach to the historiography of Brazilian \\ colonial architecture: the ideas of John Bury
}

por Mariela Brazón

\section{RESUMO}

0 objetivo central deste artigo é expor um estudo detalhado da obra historiográfica do inglês John Bury, quem dedicou uma parcela importante da sua produção à arte e à arquitetura colonial brasileira. Foram identificadas e analisadas as bases conceituais e metodológicas do trabalho de Bury, especialmente no tocante a questões de estilo, periodização, contextualização e correlação dos fatos estudados com outros fenômenos artísticos oriundos do mundo europeu e hispano-americano, o que permitiu avaliar as hipóteses levantadas pelo autor sobre questões conceituais, tais como "originalidade" e "identidade". Foram estabelecidos paralelismos com as ideias de outros historiadores europeus e latino-americanos - como Germain Bazin, Ramón Gutiérrez e Damián Bayón - com o intuito de compreender os tópicos discutidos dentro do amplo panorama da historiografia da arte da América Latina. Desta maneira, o estudo apontou a relevância da produção estudada e mostrou a necessidade de valorizá-la fora dos lineamentos abertos pela historiografia modernista.

Palavras-chave John Bury; historiografia da arte colonial; arquitetura brasileira

\section{ABSTRACT}

This paper presents a detailed study of the historiographical work of John Bury, who devoted a significant part of his production to Brazilian art and colonial architecture. We identified and analyzed the conceptual and methodological basis of Bury's work, especially regarding problems of style, periodization, contextualization and correlation between the studied facts and other artistic phenomena from the European and Spanish American worlds. This made possible the evaluation of the hypotheses raised by the author on conceptual matters, such as "originality" and "identity". We established parallels between the ideas of Bury and those of other Europeans and Latin Americans historians - as Cermain Bazin, Ramón Gutiérrez, and Damian Bayon - in order to understand the topics discussed within the broad context of the historiography of Latin American art. Hence, this study showed the relevance of Bury's work and pointed out the importance of appreciating his production far from the outlines of modernist historiography.

Keywords John Bury; historiography of colonial art; Brazilian architecture 
Quando em 1934, o historiador John Bury teve contato inicial com o passado colonial ibero-americano, através do texto de Sacheverell Sitwell (Spanish baroque art, 1931), a historiografia sobre a arte brasileira dava ainda seus primeiros e tímidos passos. 0 jovem inglês não podia imaginar que esse encontro, aparentemente tangencial, seria a semente de um interesse duradouro pelo mundo artístico luso-americano que daria frutos valiosos, estendendo-se durante várias décadas. Seu meio familiar, estreitamente ligado à vida acadêmica, e a formação em História da Arte Moderna (0xford, 1935-38) ajudaram a consolidar as bases de suas pesquisas, centradas principalmente no império colonial português, na cultura do século XVI e nos jardins europeus.

Bury teve a oportunidade enriquecedora de viajar e conhecer diretamente as obras que até esse momento tinham despertado sua curiosidade só no plano teórico; isto, porque seu trabalho numa companhia petroleira obrigou-o a se trasladar a certas localidades sul-americanas, dentre elas, várias cidades brasileiras. A breve estada neste país, entre 1947 e 1948, foi altamente produtiva para o desenvolvimento da historiografia local. Quatorze meses foram suficientes para que o pesquisador conhecesse povoados e monumentos, fizesse apontamentos e compilasse dados que usaria posteriormente na redação de mais de uma dezena de artigos e de algumas obras gerais sobre arquitetura, escultura e cultura colonial. Sua aguda capacidade de observação e o amplo conhecimento da história da arte europeia fazem da sua obra um dos mais valiosos estudos sobre a arte colonial, pela sua objetividade e a abrangência dos temas.

A produção de Bury sobre o passado artístico brasileiro só começou a ser divulgada no nosso continente há poucos anos. A publicação do livro Arquitetura e Arte no Brasil Colonial (1991) colocou um ponto final no desconhecimento dos seus estudos. Graças ao esforço da sua organizadora, a professora Myriam A. Ribeiro de Oliveira, puderam ser reunidos num mesmo volume vários ensaios escritos por este pesquisador entre os anos 40 e 80, com temas vinculados à arquitetura colonial - como as relações das construções com a decoração escultórica de interiores e fachadas, o uso de termos estilísticos europeus no estudo da arte latino-americana, a aplicação de novos conceitos, como o do "estilo Aleijadinho", e, principalmente, a vida e a obra do mestre mineiro.

Além dos ensaios publicados originalmente na Europa e nos Estados Unidos, incluídos no livro Arquitetura e Arte no Brasil Colonial, Bury usou outros meios para difundir suas ideias. Sublinhemos sua participação em publicações especializadas como The Burlington Magazine, The Journal of Garden History, The Journal of the Fortress Study Group e a revista espanhola Reales Sitios, dentre outras. Também destacam as conferências ministradas na Inglaterra, na França, em Portugal e na Itália, e a participação em encontros, como o Simpósio Luso-Espanhol de História da Arte, realizado em Coimbra, e o Terceiro Colóquio Luso-Brasileiro, de Lisboa. Vale a pena lembrarmos as vezes em que o historiador foi convidado a palestrar sobre arte brasileira, nas universidades de Cambridge, oxford e Londres, eventos nos quais se concentrou na arte e na arquitetura de Minas Gerais, nos paralelos com Portugal e nas projeções das manifestações coloniais na arquitetura brasileira moderna. 
A partir dos anos 50, Bury orientou seus interesses mais diretamente para o mundo português devido à facilidade que tinha para acessar essa região. Nessa tarefa, teve 0 apoio do historiador norte-americano Robert C. Smith e do estudioso lusitano Mário Chicó, conhecedores profundos da matéria. Conforme o próprio autor relata no prefácio do livro Arquitetura e Arte ..., também teve contatos bem-sucedidos com especialistas de renome, como Nikolaus Pevsner, Rudolf Wittkower e René Taylor. Em 1970, Bury foi responsável pela redação dos verbetes relativos à Espanha, Portugal e América Latina do Oxford Companion to Art, e, posteriormente, em 1982, publicou no Guia Azul um estudo da arte e da arquitetura portuguesas, desde as origens até os tempos contemporâneos.

Nos anos 60, John Bury se viu na necessidade de organizar sua própria biblioteca sobre assuntos artísticos. Foi assim que começou a reunir um acervo precioso de obras bibliográficas antigas, especialmente de tratados arquitetônicos, que 0 ajudaram a compreender, por meio de fontes primárias, a teoria da arte europeia. A informação compilada permitiu-lhe distinguir e traçar várias linhas da arte luso-brasileira, contemplando o passado colonial do Novo Mundo através de um prisma mais universal. Essa projeção da realidade ibérica além das suas fronteiras, na qual se observa respeito e admiração pelos fenômenos locais, é um dos traços que caracterizam a obra do historiador inglês.

Os primeiros artigos que Bury escreveu sobre Antônio Francisco Lisboa apareceram no Boletim Shell, v.4 de 1948, quando ainda se encontrava no Brasil. Diz 0 autor que eles não tinham nenhuma pretensão acadêmica; foram, aliás, textos curtos com perfil jornalístico, muito bem ilustrados, que posteriormente publicou a Shell Magazine, em Londres. 0 estudo específico da obra do Aleijadinho é um assunto que sempre atraiu a atenção de Bury, e sobre o qual reuniu dados nas suas visitas a Minas. Numa ocasião, relata 0 inquieto viajante, teve 0 "privilégio extraordinário" de ver pessoalmente os ossos do artista mulato, mostrados pelo sacristão da Igreja Matriz de Antônio Dias. Também pôde conversar com Rodrigo Melo Franco de Andrade, diretor-fundador do Instituto do Patrimônio Histórico e Artístico Nacional, sobre a importância de estudar objetivamente a obra do Aleijadinho, sem cair em exageros nem sensacionalismos, amiúde associados à doença que 0 artista sofrera nos últimos anos da sua vida.

\section{A abordagem formalista na obra de John Bury}

Como historiador da arte, John Bury combina duas linhas metodológicas: a biográfica e a formalista; esta última é o eixo central do seu pensamento, pois acredita que conduzir a análise de uma obra de arte partindo dos aspectos formais é a base necessária para um estudo "objetivo". Bury se concentra em um ou mais elementos formais arquitetônicos, e vai "seguindo o rasto" da maneira como eles mudam ao longo do tempo, apoiando-se em livros teóricos, tratados e fontes iconográficas. 
Primeiro, classifica os monumentos de acordo com uma certa tipologia - que, no caso das construções religiosas brasileiras, se resume a cinco grupos básicos: 1) catedrais e igrejas matrizes, 2) igrejas de conventos, 3) capelas de ordens terceiras, 4) capelas em cidades e vilas, incluindo as de irmandades, 5) capelas notáveis, localizadas em missões, fazendas, engenhos e estâncias. Depois, seleciona entre os edifícios de cada grupo aqueles que considera mais representativos para a análise (com a intenção de efetuar um "estudo de casos"). Em seguida, para cada obra escolhida, e já identificados os aspectos gerais, como datas, autor(es) e localização, estuda os rasgos mais importantes da planta, elevação, cobertura, fachada, arremates exteriores, decoração (tanto interna quanto externa), organização espacial, tratamento do volume, da escala e da composição, materiais, técnicas etc. Este estudo formal vai acompanhado de referências complementares sobre o entorno social, econômico e político, e de dados biográficos sobre os artistas (quando conhecidos). Ao longo da descrição, o autor insere alguns comentários sobre possíveis antecedentes americanos e/ou europeus (ibéricos e não ibéricos) para os elementos que considera mais relevantes do ponto de vista arquitetônico, estabelecendo associações com a teoria artística que chegou às colônias.

Quase recorrentemente, Bury procura uma possivel "linha evolutiva" na configuração formal de plantas, fachadas, torres laterais, colunas (ex. as salomônicas) e outros elementos arquitetônicos sobre os quais propõe hipóteses. A busca das cabeças de série' levou-o até a produção artística portuguesa, centro-europeia e italiana: fontes de onde, acredita, bebeu significativamente a arte colonial brasileira. Achar essas raízes, entretanto, não foi impedimento para que Bury defendesse a existência de uma linha formal "original" na arquitetura luso-americana, que usaria elementos preexistentes organizando-os de maneira inédita - linha exemplificada nas obras do Aleijadinho.

Ilustremos, com dois exemplos, como Bury usa o conceito de séries evolutivas:

a. Exemplo de identificação de uma série formal:

Pode-se, portanto, estabelecer uma seqüência clara no desenho das fachadas das igrejas jesuíticas do Brasil. Do frontão sem torres do século XVI aos campanários encostados às fachadas do início do século XVII e às soluções intermediárias do século XVII e início do XVIII - com as duas torres escamoteadas em segundo plano - chegou-se finalmente aos genuínos projetos de duas torres, em seqüência lógica de desenvolvimento. (1991b, p.55)

1 George Kubler, historiador norte-americano da arte e da cultura, propôs em The Shape of Time (1962), um método para organizar os objetos feitos pelo homem (inclusive os objetos de arte) em função das características formais, e que permitiria estruturar sequências (séries) de obras para serem "lidas" conforme o interesse do pesquisador. 0 termo "cabeça de série" refere-se à obra (ou obras) que está (ão) na origem da série. 
b. Exemplo de identificação de cabeças de série:

... a planta [da igreja de Nossa Sra. do Rosário de Ouro Preto] encontra paralelo em Strambino, a fachada arqueada tem precedentes em Salzburgo, Einsiedeln e Weingarten, e as torres redondas, em Bade, perto de Potschatek. (1991d, p.126)

\section{A questão das plantas poligonais e curvas}

0 historiador John Bury também se concentrou no estudo das plantas poligonais e curvilíneas brasileiras, sem deixar de incluir nas suas análises, referências aos exemplos hispano-americanos mais importantes. Por ser este um assunto vinculado ao papel dos tratados arquitetônicos na Colônia - tema do seu interesse -, as observações são extensas e detalhadas.

Baseado em documentos históricos, Bury estudou os edifícios religiosos da região de Minas Gerais e chegou à conclusão de que existem três grupos de construções, bem definidos do ponto de vista estilístico: primeiramente, as igrejas matrizes e catedrais, que representam uma "retomada tardia e provinciana" da arquitetura maneirista; um segundo grupo de igrejas, pertencentes ao "estilo Aleijadinho", isto é, que apresentam características rococós locais; e um terceiro grupo, com plantas pouco comuns na arquitetura colonial ibero-americana, nas quais se observam linhas côncavas e convexas acentuadas, típicas do estilo barroco. Bury opina que os monumentos do terceiro tipo não são obras de transição entre o primeiro e o segundo grupo; isto significa que as plantas estritamente barrocas seriam um episódio até certo ponto independente, associado à atuação de arquitetos que demonstraram uma erudição pouco comum na época e que se inspiraram em projetos provenientes da Europa (possivelmente de origem italiana ou austríaca). Essas interessantes construções teriam sido alvo de leituras errôneas, devido ao pouco conhecimento das fontes primárias. Para tentar esclarecer 0 assunto, Bury procura as possíveis origens portuguesas, concluindo que também nas metrópoles esse tipo de construção foi escasso, e que no caso lusitano, projetos com essas características são, em geral, atribuídos a arquitetos estrangeiros. 0 caso mais representativo no Brasil é a igreja de Nossa Sra. do Rosário, em Ouro Preto, sobre a qual Bury argumenta: “...o desenho do Rosário, baseado em arrojadas curvas convexas, se diferencia nitidamente tanto da retangularidade do maneirismo como das formas sinuosas e suaves do rococó mineiro." (1991d, p.119)

Uma questão por muito tempo aberta para os historiadores da arte colonial brasileira é se existe ou não uma sequência que coloque as plantas poligonais como antecedente direto das plantas curvilíneas. Bury destaca que esta poderia ser uma hipótese coerente, mas que parece muito pouco provável que os arquitetos portugueses favorecessem este tipo de evolução, visto que a preferência lusitana esteve sempre orientada às plantas retas. $\mathrm{A}$ isto acrescenta que existem exemplos 
que permitem duvidar que as plantas elípticas sejam o "desenvolvimento lógico" das plantas poligonais alongadas. Um destes exemplos é a igreja de São Pedro dos Clérigos, no Rio de Janeiro (1733-demolida em 1942), templo com características morfológicas que vão além de um simples alongamento da nave central. Bury destaca nela, não só a forma oval da planta, mas também as linhas curvas muito acentuadas das capelas laterais, da fachada e das torres, o que a diferenciaria "não apenas em grau, mas em espécie" dos templos lusitanos poligonais ou curvilíneos. (1991d, p.121)

John Bury não conseguiu dar respostas a todas as questões vinculadas às plantas retas e curvilíneas. Não chegou a esclarecer, por exemplo, por que as plantas curvas tiveram tanta aceitação em Minas Gerais e no Rio de Janeiro, sendo rejeitadas em outras regiões do mundo lusitano. A explicação mais satisfatória que encontrou foi ver na pouca atividade sísmica em Minas Gerais, um fator favorável a esse tipo de construção; porém, este não parece ser, por si só, um argumento suficiente, visto que em outras partes do território brasileiro os movimentos de terra também são pouco frequentes.

\section{A classificação estilística e a periodização da arte colonial}

John Bury dedicou um dos seus últimos artigos sobre a arte ibero-americana ao uso de termos estilísticos (1991h), considerando que o assunto não tinha sido debatido suficientemente em relação ao mundo luso-brasileiro. Nesse texto, aponta para o fato de que um mesmo estilo pode ser definido de forma diferente por vários autores, o que obrigaria os historiadores a especificar qual a acepção terminológica adotada. Visto que as perspectivas para estudar a obra de arte são múltiplas, é preciso, afirma, deixar claro o significado dos conceitos usados; por exemplo, ao falar de maneirismo, deveríamos especificar se a definição corresponde à de Pevsner ou à de Lotz; ao referir-nos a monumentos barrocos, seria necessário indicar se os critérios adotados são os de Blunt, Dvoràk ou Balet. Bury é ciente das dificuldades ao delimitar os termos estilísticos, e, por este motivo, prefere defini-los em função das características formais das obras e não do conteúdo espiritual (intenções, aspirações e filosofia dos clientes e dos autores, bem como as reações intelectuais e emocionais provocadas pelas obras); e adverte: “...quanto maior abrangência for dada ao significado de um termo estilístico além de seu sentido original, tanto menor será a precisão deste mesmo significado." (1991h, p.194)

0 problema de como definir periodizações no estudo da arte é um assunto que tem despertado o interesse dos historiadores da época colonial. Bury recomendava não adotar critérios fechados de datação e periodização. Seu melhor exemplo se refere ao barroco, que não deveria, conforme sua opinião, ser confinado a um período específico, pois existem obras com características "barrocas" produzidas 
fora dos séculos XVII ou XVIII. Dessa maneira, o autor compartilha o ponto de vista do filósofo catalão Eugenio D’0rs (1964), para quem o barroco seria um fenômeno presente em vários momentos históricos.

A periodização da arte colonial provoca até hoje divergências entre os pesquisadores. Alguns, como o argentino Ramón Gutiérrez, reconhecem que a concepção do tempo americana era muito diferente da europeia, e que, portanto, igualar os dois sistemas conduziria fatalmente ao uso de adjetivos inadequados para a arte colonial - como o de "anacrônica". Gutiérrez sugere aos historiadores do período colonial não se submeter a categorias espaço-temporais excessivamente rígidas, que impeçam a liberdade de análise, e, como também fizera seu conterrâneo, o historiador Damián Bayón, critica abertamente os pesquisadores que "forçam" os dados para fazê-los corresponder com as divisões cronológicas e/ou temáticas usadas para a arte europeia.

Quando se trata de critérios para definir periodizações, a obra de Bury resulta bastante elucidativa. Para abordar cronologicamente a história artística das colônias portuguesas, considera útil a periodização por "ciclos econômicos", divisão bastante usada nas histórias gerais, que considera o século XVI como o século do comércio das espécies, cujo centro urbano principal esteve na cidade de Velha Goa, na Índia; o XVII, como o século do açúcar, com o maior desenvolvimento nas regiões da Bahia e Pernambuco; e finalmente, o XVIII, como o século do ouro, que atingiu seu auge nas cidades de Minas Gerais. Acrescenta o autor (1991f, p.72): “... são nesses antigos centros de comércio [...] que se encontram as mais interessantes e ambiciosas manifestações de arquitetura lusitana fora de Portugal nos séculos XVI, XVII e XVIII...".

Para periodizar a arquitetura de uma região específica, digamos a região mineira, Bury prefere basear-se em critérios tipológicos (neste caso, a preponderância de um determinada construção). Nessa região distingue três grandes fases: $1^{\circ}$ ) a das capelas (que se inicia no século XVII), $2^{\circ}$ ) a das igrejas matrizes (que se inicia no século XVIII) e $3^{\circ}$ ) a das igrejas do Aleijadinho (que abrange $o$ último quartel do século XVIII e o primeiro do século XIX); sem esquecer que houve uma fase de transição entre o maneirismo das matrizes e o rococó local.

Se concentrarmos nossa atenção na obra de um artista, como, por exemplo, o Aleijadinho, veremos que Bury delimita o estudo segundo as fases da vida profissional: 1Ć) a que abrange suas principais realizações arquitetônicas (1770-1794), 2ć) a que contempla seu trabalho como escultor de imagens (nos Passos e no adro de Congonhas), época em que se faz evidente a progressão da doença (1795-1807), e 3ć) sua etapa final, na qual, estando incapacitado por causa da enfermidade, limita-se a dirigir os trabalhos dos seus oficiais (1807-1812).

Podemos observar, então, que Bury adota três tipos de periodização, dependendo do estudo: uma, com base em critérios econômicos; outra, em função das características morfológicas; e uma terceira, que acompanha os dados biográficos do artista e aponta a uma espécie de curva "biológica", na qual as etapas de maturidade artística são seguidas de uma fase final de doença e morte. 
Com relação a este último tipo de critério, vale a pena comentar que George Kubler o criticou em repetidas ocasiões, sugerindo aos historiadores da arte usar com extremo cuidado as metáforas provenientes de outras áreas do conhecimento - em especial as do tipo biológico -, não pelo fato de pertencerem a campos extra-artísticos, mas por serem, em muitos casos, pouco objetivas. Kubler (1975, p.70 et seq) propõe substituir o esquema evolutivo pela noção de "idade sistemática", isto é: a medida do grau de desenvolvimento que uma forma (técnica, objeto de arte etc.) alcança num momento determinado, em relação à linha completa da sua existência. Com isto, substituir-se-ia a idade biológica, absoluta, por um posicionamento relativo, determinado em função da démarche do próprio fenômeno artístico (fase inicial, intermediária ou tardia).

\section{Os estilos maneirista, jesuítico e da Contra-Reforma}

John Bury identificou vários inconvenientes no uso do termo "maneirismo" no contexto latino-americano. A acepção do vocábulo remete, segundo a maioria dos autores, a uma arte criada para quebrar intencionalmente as normas clássicas. Assim, opina que nem sempre é possível afirmar que o distanciamento dos princípios clássicos aconteceu nas colônias ibéricas com plena consciência, pois amiúde esses princípios eram desconhecidos pelos arquitetos locais; e sustenta que as supostas "rupturas" podem na verdade ser "defeitos", característicos de produções "provinciais" (1991h, p.199). Sobre o maneirismo, Damián Bayón (1989, p.86) tinha uma opinião similar à de Bury, sendo enfático ao afirmar que muitos monumentos latino-americanos denominados "maneiristas" não são realmente desse estilo, pois, o que à primeira vista parecem ser modificações conscientes de cânones clássicos, realmente seriam o produto da desinformação ou da ausência de mão-de-obra especializada - fatos comuns nas colônias.

Este e outros problemas causam conflitos no uso do termo "maneirismo"; porém, essa expressão está tão arraigada na literatura especializada que, ainda hoje, resulta difícil bani-la do glossário historiográfico da arte colonial. Bury (1991h, p.197) não deixou de usá-la, advertindo que preferia restringi-la a “instrumento analítico valioso à pronta identificação de características anticlássicas em edifícios que aparentemente pertencem à tradição clássica". Evitou-a ao se referir à arquitetura luso-brasileira feita entre 1570 e 1710, adotando em seu lugar a expressão "estilo da Contra-Reforma".

Sobre a presença da Companhia de Jesus ${ }^{2}$ nas colônias portuguesas, o trabalho de John Bury foi realmente prolífico. Nas suas primeiras obras historiográficas, refere-

2 "A Companhia de Jesus" ou simplesmente "A Companhia" é a ordem dos jesuítas; chamada assim devido à estrita disciplina dos seus membros, organizados como se fossem soldados ao serviço do Papa e de Deus. 
-se ao "estilo jesuítico" como aquele que abrange um conjunto de construções, levantadas entre os séculos XVI ao XVIII na Europa, no Oriente e na América, que apresentam "serenas superfícies retangulares tanto em planta quanto nas elevações e desenho dos vãos", além de "ausência de decoração externa, compensada por uma espantosa exuberância na ornamentação interna" (1991g, p.28). É um estilo que chegou ao Brasil diretamente de Portugal, e sua influência sentiu-se principalmente nas igrejas seiscentistas de cidades litorâneas, por estarem mais ligadas à metrópole. 0 curioso - aponta Bury - é que o termo foi usado por alguns historiadores brasileiros (ex. Lúcio Costa) para se referir a edifícios que não necessariamente têm relação com a ordem jesuíta, ou que, inclusive, foram construídos em regiões onde os padres inacianos não chegaram a se estabelecer, como é o caso de Minas Gerais. Sobre o assunto, comenta (1991b, p.57): “... a predominância do clero jesuíta em assuntos intelectuais e artísticos da colônia era tão indiscutível que o uso impróprio no Brasil do termo estilo Jesuítico para descrever o caráter da antiga arquitetura mineira não deixa de ser significativa".

Bury quis construir as linhas evolutivas da arquitetura jesuítica. Detectou "cabeças de série" em Lisboa (como a igreja de São Roque) e possíveis intercâmbios entre arquitetos da ordem e colegas portugueses e italianos. Viu na ordem de Santo Inácio "o canal de transmissão mais influente da cultura europeia para a América portuguesa" durante o primeiro período colonial (1991b, p.43). Assinalou e descreveu monumentos importantes construídos pela ordem, não só no Brasil, mas também na Índia e na China, lamentando a perda de muitos desses edifícios no território americano. Afortunadamente, dizia, os pesquisadores que desejem estudar 0 desenvolvimento do estilo no século XVI e início do XVII, contam com monumentos bem conservados em Portugal e no Oriente.

Entre os problemas formais da arquitetura jesuítica mais estudados por Bury, esteve o "conflito" entre o modelo de fachada da igreja de II Gesu, em Roma, e as torres laterais, à maneira de São Vicente de Fora, em Lisboa; conflito resolvido em algumas igrejas brasileiras. Outra questão abordada pelo autor é a presença de mão-de-obra indígena nas construções localizadas em regiões limítrofes do Brasil, citando nesse sentido a igreja de Sto. Alexandre, em Belém do Pará, zona que foi "base avançada para sua mais ambiciosa ocupação do interior da América do Sul: as missões indígenas na bacia do rio Amazonas" (1991b, p.52).

Bury destaca também as diferenças existentes entre a arquitetura da ordem jesuíta nas colônias hispano-americanas e nas lusitanas, diferença que derivou, em boa parte, das diversidades já existentes entre a Espanha e Portugal. 0 historiador concorda com o jesuíta Joseph Braun ao afirmar que esta ordem religiosa se adaptou aos estilos, sentimentos e ideias dos povos onde atuava, fazendo interpretações regionais que não deixavam de refletir o espírito geral da Companhia de Jesus.

Uma questão importante colocada por Bury é o motivo pelo qual os jesuítas não usaram no Brasil estilos arquitetônicos mais "modernos", como o barroco. Acredita que a melhor hipótese para responder a essa interrogação (além da quase 
indiferença da arte portuguesa pelo barroco e sua preferência pelas formas maneiristas) é que os padres portugueses da Companhia talvez considerassem o maneirismo como um "estilo próprio", que refletia certos princípios da ordem, como o respeito pela disciplina e a expurgação dos elementos pagãos, bem como seu papel educativo e missionário. É interessante lembrar que na América Hispânica, a ordem jesuíta demonstrou maior preferência pelas formas barrocas, evidentes em igrejas da Companhia como a localizada em Quito, dentre outras.

Ao longo da sua obra historiográfica, Bury vai abandonando progressivamente 0 termo "jesuítico", preferindo substituí-lo pela expressão "estilo da Contra-Reforma", sem esquecer que já antes da Primeira Guerra Mundial, Braun afirmara que não existia um "estilo arquitetônico jesuíta" (BURY, 1991h, p.199). Assim, o historiador inglês achou mais conveniente concentrar-se na ideologia tridentina subjacente a esses monumentos, do que recorrer a um termo que pudesse remeter à produção de uma ordem religiosa, muitas vezes nem mesmo envolvida na criação dos edifícios.

\section{A questão do estilo barroco na América Latina: estrutura versus ornamentação}

Desde que Denise Diderot, na Enciclopédie (1718), associou o barroco com os adjetivos "bizarro" e "excessivo", até que Heinrich Wölfflin, no início do século XX, o reconheceu como um fenômeno com características próprias, mostrando que não deveria ser estudado como simples "degeneração" da arte renascentista, o estilo sofreu severas críticas, produto de ideologias que privilegiavam a normativa clássica. Contudo, a publicação de Conceitos fundamentais da história da arte (1915) não fez com que os qualificativos negativos cessassem - como provam os juízos emitidos por Benedetto Croce -, e as polêmicas sobre a melhor definição do termo continuaram até bem avançado o século XX.

A caracterização do barroco (formal e conceitual) é um assunto sobre o qual nem sempre houve consenso entre os historiadores, pois as tentativas de defini-lo estilisticamente procuram dar conta de fatores complexos, como sua morfologia heterogênea, o amplo alcance geográfico e cronológico, e sua intricada essência ideológica. Sobre estas dificuldades, Jan Bialostocki (1966, p.9) lembra:

Cuando se quiso organizar en 1956 una exposición sobre el arte europeo de la llamada época Barroca (a continuación de las exposiciones dedicadas al Renacimiento y al Manierismo) se hizo evidente que los organizadores no podían ponerse de acuerdo sobre este término de «barroco europeo». Finalmente, la exposición, que tuvo lugar en Roma en febrero de 1957, fue inaugurada con el nombre de Seicento europeo.

Para alguns historiadores, como Bury, o barroco na América Latina é um fenômeno, acima de tudo, formal, que responde à intenção de criar ambientes dinâmicos e 
de complexa exuberância. Afirma também que a essência do estilo é a busca de "resultados dramáticos", "ilusão do ilimitado" e "teatralidade". Para atingir esses alvos, usam-se na arquitetura recursos formais como linhas curvas em oposição aguda côncavo-convexa, composições que sublinham o efeito surpresa e contrastes fortes de iluminação, dentre outros. Bury aponta para a existência de um barroco "arquitetônico" e de outro "decorativo", e não duvida ao afirmar que o segundo é tão autenticamente barroco quanto o primeiro, pois através da ornamentação podem ser construídos espaços internos muito dinâmicos.

Bury (1991d, p.129) denomina de "borromínicos" os edifícios coloniais com plantas baixas curvas e espaços movimentados. Note-se que essas duas características podem estar presentes não só em monumentos barrocos, mas também em construções rococós; portanto, "borromínico" é um termo que transcende o estritamente estilístico. 0 autor dedicou-se a identificar os monumentos do Brasil colonial que correspondessem a essa tipologia, bem como a analisar sua composição arquitetônica, determinar suas variantes e examinar as fontes que possivelmente contribuíram para sua aparição e evolução. Sobre essa questão, expôs suas afirmações na forma de hipóteses, devido à falta de evidências documentais.

Quando Bury aborda o barroco colonial, estuda o comportamento dos elementos tectônicos e decorativos - que ajudam a desintegrar os contornos e a dissolver os pontos de referência estruturais; princípios assinalados pelo autor como característicos do estilo. Deu atenção às colunas salomônicas e às pilastras misuladas, que transmitem sensação de instabilidade; aos tetos em trompe l'oeil, que estendem infinitamente o espaço; e aos elementos exteriores: enquadramentos de portas e janelas, bem como os dinâmicos arremates de torres e fachadas.

Bury sabe que no Brasil, bem como na América Hispânica, o barroco foi raro na dimensão espacial estritamente arquitetônica, estando mais concentrado na decoração. Nos seus escritos valorizou a ornamentação como um dos elementos com mais poder para provocar uma determinada sensação espacial. Ele se baseia, como também fez Germain Bazin, no fato de o barroco transmitir impressões de irrealidade, desintegrando os contornos estruturais mediante variados recursos, como por exemplo, a talha interna e a pintura de forros em trompe l'oeil. Por ser um estilo que comunica instabilidade, o barroco dá preferência a elementos decorativos "visualmente instáveis", como a estípite e a coluna salomônica. Com suas próprias palavras (1991a, p.187):

o objetivo artístico [da decoração interna] é mais preciso e específico: desfazer a impressão [...] de que o visitante «se encontra em um grande galpão», sensação que a ingenuidade arquitetônica deste espaço em paralelepípedo produz. o retábulo, com seus minuciosos entalhes e rico revestimento dourado, atrai o olhar magneticamente, ampliando o espaço e dissolvendo seus limites, com sugestões de vibração e movimento.

Podemos pensar, então, que Bury vê os elementos da decoração interna - e em especial os retábulos barrocos - como mais do que simples peças decorativas, 
reconhecendo que participam ativamente na dinamização do espaço. Basta tomar como exemplo os retábulos abertos, que substituíram os delimitados por molduras, contribuindo assim para a eliminação das fragmentações espaciais. Quando se trata do exterior, Bury também identifica elementos ornamentais que acentuam a movimentação - como os frontões com volutas.

\section{0 "estilo mestiço" e o "estilo Aleijadinho"}

São vários os historiadores europeus - como Germain Bazin e John Bury - que não tiveram objeções contra o uso de termos aceitos na historiografia da arte europeia, no estudo da arte colonial latino-americana. No entanto, Bury considerou necessário especificar em um dos seus artigos (1991h) os fatos que deveriam ser levados em conta ao usar a terminologia tradicional, acrescentando comentários sobre a nomenclatura estilística criada especialmente para configurações que, em sua opinião, existiram apenas no mundo americano. Aceitou, assim, que a historiografia sobre a América Latina criasse ferramentas e conceitos próprios que pudessem dar conta da arte do Novo Mundo, sem, contudo, rejeitar as concepções de origem europeia.

A questão de se existe ou não uma "arte mestiça" foi discutida de maneira diferente na historiografia das colônias lusitanas e na das colônias hispânicas. Nesta última, o termo refere-se, principalmente, à indigenização presente em certas obras hispano-americanas; tema tocado em profundidade por historiadores como Francisco Stastny (1994). No contexto brasileiro, Germain Bazin (1989, p.383) destacou que, se aqui existiu algum tipo de "arte mestiça", não foi o produto da influência indígena, mas, sim, da poderosa marca dos negros. Bury (1991f, p.71) aceitou 0 conceito, mas o usou apenas para se referir à mistura de elementos artísticos europeus e indígenas que detectou em regiões periféricas da América Hispânica, mais exatamente nos Vice-reinos da Nova Espanha e do Peru.

0 termo "estilo Aleijadinho", por sua vez, foi usado por Bury para designar a arquitetura rococó construída na região de Minas Gerais entre ca. 1770 e 1820. Lembremos que o rococó é um estilo internacional que se distingue justamente por apresentar caracterizações locais muito variadas, e o estilo Aleijadinho seria, segundo Bury, uma delas. A origem da expressão parece remontar a 1946, quando Ludwig Waagen o usou "de maneira um tanto vaga" num jornal de Belo Horizonte (BURY, 1991d, p.131). A partir de 1955, Bury ocupou-se de definir com precisão o termo e de difundir a nova categoria de análise.

0 "estilo Aleijadinho" toma seu nome do artista que foi seu maior expoente, embora, como explica Bury, também pertençam a ele algumas construções realizadas por outros artistas mineiros sob a mesma linha formal. 0 termo pode ser usado não só para manifestações arquitetônicas ou escultóricas, mas também para obras pictóricas, como as realizadas por Manuel da Costa Ataíde na decoração interna de igrejas (1991f, p.77). No artigo que Bury dedica exclusivamente aos estilos da 
arte colonial luso-brasileira (1991h, p.202), explica que foi necessária a criação do termo porque existia um conjunto de obras com características barrocas e rococós que merecia uma denominação estilística própria.

Sobre o viés barroco do estilo, sublinha (1991g, p.29):

[0 Aleijadinho] captou instintivamente as noções básicas do barroco em termos de movimento, ausência de limites e espaço teatral, assim como a ideia de que todas as artes, arquitetura, escultura, talha, douramento, pintura, e até mesmo espetáculos efêmeros, [...] deveriam ser usados como elementos que contribuíssem harmoniosamente para um grandioso efeito ilusório.

E acrescenta as seguintes características rococós: linhas curvas com sofisticada continuidade entre as orientações côncavas e convexas, elegante ornamentação em relevo aplicada às fachadas e decoração interior "mais contida do que no estilo jesuítico" (1991f, p.77). Afirma que "o original" do estilo não são os elementos que o conformam, mas a maneira como eles são integrados: "...tratamento da ornamentação - relação de equilíbrio entre os elementos decorativos e os estruturais - bem como no gracioso efeito alcançado pelo uso de seções curvas nas paredes, harmoniosamente relacionadas entre si e com as superfícies planas adjacentes" (1991f, p.77); isto é, um tratamento compositivo que, segundo Bury, não tem igual em Portugal. As cabeças de série estariam mais próximas, em todo caso, dos projetos realizados no século XVIII nas regiões do Piemonte, da Áustria, da Boêmia e do sul da Alemanha.

Ao se referir especificamente ao uso de linhas curvas, o estilo Aleijadinho é visto por Bury como um subconjunto da arquitetura "borromínica", pouco comum na América Latina. Este fato pode ser ilustrado através de três exemplos atribuídos ao artista mulato, considerados pelo historiador como os mais representativos das características "borromínicas" da arquitetura mineira: a) fachada sinuosa (igreja de Nossa Sra. do Carmo, em Ouro Preto), b) planta elíptica (igreja de São Francisco de Assis, em São João del Rei), e c) torres laterais cilíndricas (igreja de São Francisco de Assis, em Ouro Preto).

\section{$\star * *$}

A obra de John Bury evidencia um estudo profundo das fontes europeias que nutrem a arte ibero-americana. Com a exposição de suas teses, o historiador inglês não pretendeu criar confrontos nem colocar em discussão assuntos polêmicos, como foi característico na historiografia contemporânea local. A não ser quando exalta a originalidade da obra do Aleijadinho, Bury teve um olhar distanciado da linha modernista brasileira, estando mais inclinado a identificar as raízes formais e as fontes teóricas que pudessem explicar a origem dos monumentos arquitetônicos locais.

Seus escritos correspondem a uma etapa na qual começavam a internacionalizar-se os estudos sobre a arte latino-americana, o que provavelmente explique porque não chegou a problematizar em primeira instância, como os historiadores hispano-americanos, a relação "sociedade colonial / obra arquitetônica", preferindo colocar 
o contexto político e econômico como um "pano de fundo" dos acontecimentos artísticos. Contudo, sua visão dos fatos foi suficientemente aguda como para despertar reflexões críticas sobre pontos comumente aceitos na literatura tradicional. A ênfase que John Bury colocou na busca das raízes formais e conceituais dos objetos arquitetônicos, sem cair em louvores nacionalistas excessivos, prova que a originalidade da arte latino-americana é um assunto que pode ser tratado sem omitir ou colocar em segundo plano as contribuições provenientes de outros territórios. 


\section{Referências}

$>$ BAYÓN, Damián. et al. Historia del arte colonial sudamericano. Barcelona: Polígrafa, 1989.

> BAZIN, Germain. A arquitetura religiosa barroca no Brasil. Rio de Janeiro: Record, 1983. 2 v. [1ed. 1956].

$>$ História da história da arte. São Paulo: Martins Fontes, 1989. [1ed. 1986].

> BIALOSTOCKI, Jan. El "Barroco": estilo, época, actitud. Boletín del Centro de Investigaciones Históricas y Estéticas, n. 4, Caracas: UCV, 1966, p. 9-36.

> BURY, John. A arquitetura e a arte do Brasil colonial. In: Arquitetura e Arte no Brasil Colonial. São Paulo: Nobel, 1991a, p. 162-191. [1ed. 1984]. - A arquitetura jesuítica no Brasil. In: Arquitetura e Arte no Brasil Colonial. São Paulo: Nobel, 1991b, p. 43-61. [1ed. 1950]. . Antônio Francisco Lisboa, o Aleijadinho. In: Arquitetura e Arte no Brasil Colonial. São Paulo: Nobel, 1991C, p. 62-70. [1ed. 1951]. . As igrejas «Borromínicas» do Brasil Colonial. In: Arquitetura e Arte no Brasil Colonial. São Paulo: Nobel, 1991d, p. 103-135. [1ed. 1955].

$>\quad .0$ Aleijadinho. In: Arquitetura e Arte no Brasil Colonial. São Paulo: Nobel, 1991e, p. 15-24. [1ed. 1949].

$>$ > 0 «Estilo Aleijadinho» e as igrejas setecentistas brasileiras. In: Arquitetura e Arte no Brasil Colonial. São Paulo: Nobel, 1991f, p. 71-83. [1ed. 1952]. , . Os doze profetas de Congonhas do Campo. In: Arquitetura e Arte no Brasil Colonial. São Paulo: Nobel, 1991g, p. 25-42. [1ed. 1949]. . Termos descritivos de estilos arquitetônicos com especial referência ao Brasil e a Portugal. In: Arquitetura e Arte no Brasil Colonial. São Paulo: Nobel, 1991h, p. 192-206. [1ed. 1989].

> D'ORS, Eugenio. Lo Barroco. Madrid: Aguilar, 1964. [1ed. 1931].

> GUTIÉRREZ, Ramón. Arquitectura y urbanismo en Iberoamérica. Madrid: Cátedra, 1997.

> KUBLER, George. La configuración del tiempo. Madrid: Alberto Corazón, 1975.

> STATSNY, Francisco. ¿Un arte mestizo? In: BAYÓN, Damián (Relator). América Latina en sus artes. 8. ed. México: Siglo XXI, 1994. 237 p. p. 154-170.

> WÖLFFLIN, Heinrich. Conceitos fundamentais da história da arte. São Paulo: Martins Fontes, 1996. [1ed. 1915]. 
Mariela Brazon possui Bacharelado em Computação e Bacharelado em História da Arte, ambos pela Universidad Central de Venezuela. É Mestre e Doutora em Artes Visuais pela Universidade Federal do Rio de Janeiro. Desenvolveu pesquisa de Mestrado sobre a historiografia da arquitetura colonial sul-americana, e tese de Doutorado sobre as relações entre a arte cinética, a física e a matemática. Tem experiência em História, Teoria e Historiografia da Arte, atuando principalmente nas seguintes áreas: Relações entre Arte e Ciência, Arte Cinética e Arte Latino-americana. Na Universidad Central de Venezuela, lecionou nas áreas de Lógica Matemática e Matemáticas Discretas. Atualmente é professora adjunta de história da arte na Escola de Belas Artes da Universidade Federal da Bahia.

marielabrazon@yahoo.com.br 